\title{
Study on the Building Structure and Architectural Decoration Art of the Cave Dwellings in West Henan
}

\author{
Fuyan $\mathrm{Yu}$ \\ School of Arts and Design \\ Huanghe Science and Technology College \\ Zhengzhou, China 450063
}

\begin{abstract}
This paper investigates, analyses and summarizes the formation background, basic type, architectural layout, courtyard arrangement and decorative art of the cave dwellings in west Henan by means of literature summarization and field investigation, and explores the artistic characteristics and existing significance of the traditional earth architecture. As a typical representative of the Central Plains culture, the cave dwelling houses in west Henan have their own unique architectural style while merging with the Central Plains culture based on the Yellow River and the surrounding cultural circle, which can stimulate the vitality of the local culture in the Central Plains, and provides reference value for study on humanistic resources in the Central Plains and theory of the regional cultural characteristics.
\end{abstract} art

Keywords—cave; building structure; architectural decoration;

\section{INTRODUCTION}

Henan Province was known as "Zhongzhou" in ancient times, which in the middle and lower reaches of the Yellow River. It was high in the west and low in the east, belonging to warm temperate monsoon climate. Henan is located in the Central Plains, which is a big agricultural province, and that's why the rural areas become the province's theme. The west Henan includes Xingyang, Gongyi, Yanshi, Luoyang, Xin'an, Yima, Mianchi, Shanxian and Lingbao counties, most of which are at the elevation of 1000 to 2000 meters. Many of the prehistoric tales of Chinese civilization come from this rich land. "Shiji Suoyin" recorded that "he had the luck of soil which was yellow, so he was called the Yellow Emperor." The Yellow Emperor is the common ancestor of the people who live and work on this piece of yellow earth. In west Henan, the thickness of loess gradually increases from west to east, and the types of loess are divided into terrace, plateau and hill, distributed widely, which is the unique geographical resource for west Henan to construct caves. It is the special natural geographical condition that determines the construction method and building material of "caves", the characteristics of the characteristic traditional building in this special area and its architectural decoration art with special charm.

\section{Main Types Of CAVES In Henan Province}

Caves in west Henan are mainly distributed in Shangjie, Xingyang, Xinmi and Gongyi under Zhengzhou City and Yanshi, Luoyang suburb, Mengjin, Xin'an, Shaanxian,
Lingbao under Luoyang, etc" . Caves in west Henan are mainly divided into earth caves against mountains, earth caves with stone at the opening, and pit, generally there are more stone and brick caves in suburbs, while there are more earth caves or stone port caves in rural areas. According to its construction materials, caves in Henan are divided into earth cave, stone cave, brick cave, soil-based cave, Liubazi cave and so on. Caves in west Henan are generally built on the slopes of the loess or the foot of the mountain exposed to the sun. Based on the construction layout and structure of the cave dwelling, it is divided into three types: the cliff type, the sunken type (commonly known as pit cave, and the independent type (confine cave).

\section{A. The Cliff Cave}

The cliff caves are built in the ditch cliff area. Excavate a cave on the slope, against the mountain and cliff, distributed along the contour line, and a number of caves are arranged in line. The loess in the ditch area against the cliff is stable, and two slopes are flat, the ditch bottom is flat, the cross-section is U-shaped, based on grading, butting and digging. The cliff cave consists of: cave yard, the main cave, the side cave, inversely-set cave. The main cave is for living, the side cave is for storage and miscellaneous use, such as kitchen, granary, storage of debris, etc., and the inversely-set cave is generally used to raise livestock and as entrance gateways

\section{B. Sunken Cave}

The sunken cave is the underground cave, commonly known as the "pit yard" among the local villagers. In loess plateau where there is no hillside or trench to be used, the farmers cleverly take use of loess features, dig down about 6 meters into the ground, form square or rectangular pits in different sizes, and then cut out the cave on the four walls horizontally, to form an underground courtyard for people to live. It is a unique type of building in rural areas in west Henan, with a history of thousands of years. Such sunken cave has many titles in the west Henan cave area, such as the courtyard, pit yard, cave yard, cave manor and so on, such as in Yicun Township in Sanmenxia City, Xizhang Village in Lingbao City, and Zhongtou Village in Mangshan District, Luoyang City. 


\section{Confine Cave}

The independent cave is a type of archy house covering earth, and there is soil adobe archy cave as well as brick archy cave and stone archy cave. This cave does not need to lean against the cliff, and can sand on its own, without losing the advantages of the cave. It can be single-layered, and can also be built into building. If the upper layer is also confine cave, it is called the "cave-on-cave"; if the upper layer is a wooden structure house, it is called "house on cave". The confine cave is divided into a one-room type, two-room type, and three-room type. This kind of cave is called as "bright confine cave" in west Henan.

\section{ThE YARD Shape AND BUILDING Structure OF THE CAVE DWELlings In West Henan}

\section{A. Courtyard Space Sequence}

Henan pit is to dig a square or rectangular pit with sides 10 to 12 meters long and 6 to 7 meters deep in the flat loess, and then dig 8 to 12 holes in the wall, choose one of the holes to dig an oblique curve to the ground, as the door for residents to pass in and out. Among them, the cave facing the hole is the main cave where the elders live, on the left and right are side caves, divided into kitchen cave, animal cave, latrine cave, door cave, storage cave according to the functions. The pit yard is generally independent with a single doorway, and also there are two-pit and three-pit yards, namely a doorway connected to two to three pits. As far as the shape of the pit yard is concerned, there are only two types, square or rectangular. The shapes of the pit yard are different, with 6 holes, 8 holes, 10 holes and 12 holes, the larger the pit area is, the more cave holes. Taking pit in the south plateau in Sanmenxia as an example, 10-hole cave's pit area is $10 \mathrm{~m} *$ $10 \mathrm{~m}$. Now farmers have been following the traditional habits to flatten and calender the cave top for threshing ground and outdoor recreation site, rather than planting. So the pit yard covers too many areas, but there is still much potential for land conservation, and needs to be further improved. The cave yards in west Henan commonly have two forms to pass in and out, namely passing through slope and passing peacefully.

\section{B. Construction Practices}

The construction of pit cave is very ingenious. The cave is connected to the earth, lying in the earth, beating with the pulse of the earth, with a practical value of a quakeproof function. As for the art function, from the top down, the whole cave yard is square. Standing in the middle of the yard to see the sky, the sky is like a dome, a microcosm of heaven and earth, reflecting the beauty of the square garden, and the ancient Chinese philosophy of "unity of heaven and man", also a typical example of the harmonious coexistence of man and nature. Under the influence of the traditional culture the Eight Diagrams, the construction of the pit yard is different according to the orientation of the main cave. The pit house is called "Dongzhen house", "Xidui house", "Nanli house" and

"Beikan house" . Most of the pit yards are like that. Among them, Dongzhen house is considered to have the best orientation, and many families choose this orientation. While considering Yin-yang eight diagrams, whether the house is and the owner are in interpromoting relation in five elements shall also be considered.

\section{Structural Features}

The top of the cave is generally made into vault, the arch height and form determine its facade characteristics. To choose this roof form, in addition to the factors of culture and architectural mechanics, it's also a wise choice for the local people when facing hot summer and cold winter. Since the surface area of the semicircle is much larger than the area of the bottom, it can dilute the intensity of the sunshine during the day so that the vault temperature is much lower than the flat roof, and at night it is very conducive to the distribution of indoor heat. For the cave in the Loess Plateau region, due to natural geographical conditions and difference in economic and technical factors, the arch forms are also different. The loess has strong anti-pressure ability but weak tensile, shear and bending capacity, and the structure of the vault exactly make up the loess defects. The wisdom of traditional Chinese dwellings lies in adjusting measures to local conditions and learning from others' strong points to offset its weakness. The value of caves in west Henan uses brick masonry, thanks to the thermal insulation of soil, it can almost guarantee a constant indoor temperature.

\section{Drainage System}

The top of the sunken cave is generally flattened and calendered in order to facilitate drainage and be used as threshing and grain-sunning field, forming a public space. Some yards have a water cave about 10 meters deep, whose profile is like flasks, whose upper part is small and the lower part is big, the cave water can not only be used to water the park and wash vegetables; also can be used as a supplement to human and animal water during the drought; the yard also has a seepage well about 5.6 meters deep, mainly used to for rainwater storage and sewage discharge, due to the strong absorption of loess, after the water flows in, it is absorbed and dry quickly, in order to prevent the water from washing the wellhead, bricks are used if it's conditional, and some use stone for reinforcement, just in case.

\section{The Architectural Decoration Art Of The Cave DWELLINGS IN WEST HENAN}

Caves in Henan are famous for being simple, unsophisticated and rough with local flavor, but they are both crude but fine, and pay attention to the artistic treatment and decoration of key parts. The cave dwellings in west Henan pay attention to the artistic treatment of the door appearance, cliff protecting eaves, parapet and the slope.

\section{A. Door Appearance}

Caves in Henan integrate the cave doors and windows, narrower than the arch span of the cave, commonly known as the opening-locked cave. Caves in Henan are very particular about the door appearance, common families use tile carving curtain pattern, the arches are decorated with laminated floral brick carving, added with the curve lace beauty, and the 
sculpture theme is often the auspicious plaque of "Blessing Arriving at The Home" and "Luck", to highlight the master's elegance and cultural level. The small canopy in west Henan commonly use hexagonal brick to build up a round hole, not only with the interest of making the finishing point, but also as the exhaust window for ventilation and smoke exhaust. Some wealthy families still carve the couplets on both sides of the doors, inlaying the plaque above the neck plaque, as to show the gorgeous wealth and elegance of the entrance. Small niches are often set between the walls of the caves in the west Henan, which not only expands the using space of the cave, but also can serve as a small altar for the people to celebrate the feast of the Emperor of Heaven and the land of God.

The window paper cutting is divided into seasonal and non-seasonal types. In the past, in the Spring Festival, the windows and houses of the cave became an exhibition site for papercutting. The newly married daughter-in-law shall send their own papercutting to relatives, to show their ingenuity. Secondly, in wedding or other joyous occasions, the windows and wall of the cave were posted with paper cutting to beautify the situation and strengthen the festive atmosphere. In the past, the contents of paper cutting were mainly "Magpie on the Plum Blossom", "Peacock Spreads Its Tail" and a variety of patterns of flowers, insects, animals and birds, mostly reflecting of the yearning for a better life. The paper cutting pasted on windows were finely made, divided into five processes of painting, cutting, smoking, dyeing, and pasting. The vault thread is a decorative treatment on the outer edge along the window hole. Caves in west Henan mostly build locking arch cave on the brick cave side, with brick, stone arch thread, and some stack creasing tile in the upper part.

\section{B. Parapet and the Cliff Protecting Eave}

The parapet of the cave is to prevent people or animals from falling from the top of the cave, and the cliff protecting eave is to prevent the rain from washing the cave surface, caves in west Henan pays attention to the decoration of parts like parapet and the cliff protect eave. In the folk, the parapet is mostly made of adobe or pattern bond, and some also use rubble. The bricks are built into various tracery walls, decorating the cave side with gravel, stone, blue brick and green tile, apart form meeting the functions, it also endows the cave with more abundant local flavor in the simple beauty. The cliff protect eave can be made into one stack or several stacks, composed of wooden eaves or small green tiles on masonry eaves. The height of each stack is quite original, with great rhythm, which is an important method to decorate the cave dwelling.

\section{Gatehouse Ramps and Walls}

The gatehouse has been a key part of decoration in traditional dwellings, and people live in the cave often build as beautiful gatehouse as possible. In the sunken cave yard, ramps are also often built, and the stairs are paved with bricks, and both sides of the wall are reinforced with adobe, and then cast on smooth grass surface, and some are also directly made of bricks, and the ramp are mostly revolving or in the shape of trisquare. The householder will plant two large trees at the entrance of the ramp, and set stone roller, stone quern and stone benches under the tree, which enhance the recognition of the entrance. Many cave courtyards also have walls.

\section{CONCLUSION}

The ancient cave dwellings on Loess Plateau were living space dug out in the loess layer. This kind of architectural form belongs to "original ecology building" from the point of view of modern green ecological architecture. It is a typical example of people living in harmony with nature from the philosophical thought of "unity of heaven and man" in ancient China. The caves lean against the mountain and cliff, dig holes according to soil, taken from the nature, fused into the nature, maintaining the original ecology of the environment, which is one of the architectural types mostly consistent with the principles of modern architecture. In terms of the spatial volume classification of architectural composition theory, it belongs to underground or semi-underground buildings with much internal volume, and is adapted to the rule of subtraction. Cave dwellings adjust measures to local conditions, use local materials, adapt to climate, folklore and the needs of life, which is a native building with a rich local architectural feature. Its architectural function is reasonable, simple but thick, and the structure is integrated with construction, the content is integrated with form. It has its own regularities of distribution according to gully and deep submarine soil, showing a unique planning appearance.

Although the history of ancient dwellings can not be reproduced, we can reduce the distance between history and reality through its cultural carrier, to understand the excellent culture of the Chinese nation for thousands of years, to pursue the ancient history and culture, and organically combine historical culture with modern culture, and continue to effectively play its advantages in resources, to develop tourism, invigorate economic construction, and continue to meet the spiritual needs of modern people to experience, feel and interpret the outstanding historical culture.

\section{REFERENCES}

[1] Wang Qijun. Thirty lectures on Chinese dwellings [M]. Beijing: China Building Industry Press, 2006

[2] Hou Jiyao. Cave dwellings [M]. Beijing: China Building Industry Press, 1992. 